\title{
Scoring technique for diagnosis of ventricular hypertrophy from three orthogonal lead electrocardiogram
}

\author{
P W MACFARLANE, C Y CHEN, B BOYCE, R S FRASER \\ From University Department of Medical Cardiology, and the University Department of Pathology, \\ Royal Infirmary, Glasgow, Scotland; the Veterans General Hospital, Taipei, Taiwan; \\ and the Department of Medicine, University of Alberta, Edmonton, Canada
}

SUMMARY A prospective study for the development of scoring techniques for the diagnosis of ventricular hypertrophy from the three orthogonal lead electrocardiogram was undertaken. A total of 51 hearts was examined at necropsy in a training group on which the scoring techniques were developed and a test group of a further 82 hearts was studied to assess the sensitivity and specificity of the method. The hearts were classified as being normal or having left ventricular hypertrophy, right ventricular hypertrophy, biventricular hypertrophy, or were placed in a borderline category. These classifications were based on the measurement of the weight of the left ventricular free wall, the interventricular septum, and the right ventricular free wall. Classical electrocardiographic variables were selected and assigned a point score on the basis of their diagnostic value. The electrocardiographic diagnosis of left ventricular hypertrophy, right ventricular hypertrophy, and biventricular hypertrophy was then made when the relevant score exceeded four points. After excluding 25 cases which showed conduction defects or were regarded as borderline at necropsy, 57 cases remained in the test group for assessing the technique. The sensitivity and specificity for left ventricular hypertrophy were 65 per cent and 91 per cent, respectively. For right ventricular hypertrophy corresponding results were 53 and 90 per cent. For biventricular hypertrophy the sensitivity was lower at 42 per cent, with a corresponding specificity of 93 per cent. These results represent a considerable improvement over older techniques, with up to a tenfold increase in sensitivity being obtained. The technique can be applied with or without computer assistance.

Many investigators have attempted to establish sensitive and specific criteria for the diagnosis of ventricular hypertrophy using either the conventional 12 lead electrocardiogram or the three orthogonal lead electrocardiogram. ${ }^{1-7}$ Existing criteria are much more specific than sensitive, however. ${ }^{8} 9$ Perhaps the most successful of more recently developed criteria has been the point scoring system of Romhilt and Estes for the diagnosis of left ventricular hypertrophy from the 12 lead electrocardiogram. ${ }^{10}$ These criteria were specific at 96.7 per cent, with a sensitivity of 62.2 per cent in the training group, that is the group used to develop diagnostic criteria. ${ }^{10}$ In practice, a separate group called the test group should be used to evaluate the criteria developed from the training group. A more recent study ${ }^{11}$ based on the echocardiographic diagnosis of left ventricular hypertrophy in chronic Received for publication 28 July 1980 hypertensive patients reported a sensitivity of 42 per cent and a specificity of 100 per cent, however, for the Romhilt-Estes scoring system. Others ${ }^{12}$ have obtained corresponding results of 49 and 95 per cent, respectively. Arguably the most widely used criteria for left ventricular hypertrophy, those of Sokolow and Lyon ${ }^{2}$ (that is $S_{v_{1}}+R_{v_{5}}$ or $R_{v_{6}}$ $>3.5 \mathrm{mV}$ ), have a sensitivity of 20 to 52 per cent and specificity of 84 to 100 per cent according to various studies. ${ }^{811-14}$

The electrocardiographic diagnosis of right ventricular hypertrophy is even more difficult. ${ }^{15}$ There are no criteria which approach the ideal of good sensitivity together with a high specificity. In the study of Allenstein and Mori, ${ }^{14}$ the criteria of Myers et al..$^{16}$ had a sensitivity of 50 per cent and a specificity of 96 per cent. Those of Sokolow and Lyon $^{3}$ had corresponding figures of 79 per cent sensitivity but only 58 per cent specificity which is 
completely unacceptable, while the criteria of Goldberger $^{4}$ had corresponding values of 69 and 86 per cent.

There have been even fewer studies on combined ventricular hypertrophy which is still more difficult to diagnose from the electrocardiogram. ${ }^{15}$ Early studies showed a sensitivity ranging from 8 per cent in a study of 26 hearts $^{17}$ to 38 per cent of eight hearts. ${ }^{18}$ More recently, using statistical techniques, Gamboa et al. ${ }^{6}$ claimed 69 per cent sensitivity in separating biventricular hypertrophy from normal, left ventricular hypertrophy and right ventricular hypertrophy using training and test groups of the latter, with the original sample of 87 hearts with biventricular hypertrophy determined at necropsy remaining unchanged. When a completely different set of hearts, "clinically" with biventricular hypertrophy, was evaluated against the test normal, left and right ventricular hypertrophy hearts, that is a true test situation, sensitivity dropped to 44 per cent. Other authors have dealt with the vectorcardiographic diagnosis, without specific mention of data on sensitivity and specificity. 1920

In an attempt to improve criteria for left and right and combined ventricular hypertrophy, a study was initiated to compare the necropsy diagnosis of ventricular hypertrophy with the findings of the three orthogonal lead electrocardiogram. The aim was to develop criteria which would be highly specific yet with improved sensitivity. Because the scoring technique of Romhilt and Estes proved one of the most successful systems in this respect, a similar approach was attempted with the three orthogonal lead electrocardiogram. The earliest findings from this study were previously reported in brief ${ }^{21}$ but the present communication provides an extended test set for evaluation of the criteria, presents revised criteria, and examines in detail the question of combined ventricular hypertrophy which has a bearing on the sensitivity and specificity for the detection of right and left ven- tricular hypertrophy. This was not dealt with in the initial studies.

\section{Subjects and methods}

A total of 133 hearts was studied at necropsy. There were 75 men and 58 women, with an age range of 31 to 89 years, mean 65 years. The hearts were dissected according to the method of Bove et al. ${ }^{22}$ In brief, the left ventricular free wall, the septum, and right ventricular free wall were dissected and weighed separately. This allowed the estimation of the relative weights of the three areas of myocardium together with the calculation of a commonly used ratio $(\mathrm{LV}+\mathrm{S}) / \mathrm{RV}$, which has formed the basis of many studies relating to the post-mortem diagnosis of ventricular hypertrophy. ${ }^{23-25}$ The criteria adopted for the post-mortem diagnosis of ventricular hypertrophy either right, left, or combined were those of Bove et al. ${ }^{22}$ These criteria are summarised briefly in Table 1 .

The three orthogonal lead electrocardiogram used in the study was that which had been recorded closest to the time of death. The electrocardiograms were recorded using the modified axial lead system ${ }^{26}$ and the wave measurements were derived by computer using techniques previously published. ${ }^{27}$ The electrocardiographic interpretation available was ignored since it was based on criteria first developed a number of years ago $^{28}$ which basically used binary decision logic to determine the presence or absence of ventricular hypertrophy.

A training group of 51 hearts was initially studied. The hearts were classified into six groups shown in Table 2. The borderline group was found to be required because of the imprecise definition of hypertrophy as described by Bove et al. ${ }^{22}$ and to allow for error in the estimation of ventricular weights. The post-mortem diagnosis of left ventricular hypertrophy and right ventricular hypertrophy requires the $(\mathrm{LV}+\mathrm{S}) / \mathrm{RV}$ ratio to lie outside the range $2 \cdot 1$ to

Table 1 Criteria for post-mortem diagnosis of normal, left, right, and biventricular hypertrophy ${ }^{17}$

\begin{tabular}{|c|c|c|c|}
\hline Normal & Left ventricular hypertrophy & Right ventricular hypertrophy & Biventricular hypertrophy \\
\hline $\begin{array}{l}\mathrm{RV}<65 \mathrm{~g}(<75 \mathrm{~g} \text { if individual } \\
>70 \text { inches tall }) \\
(\mathrm{LV}+\mathrm{S}) / \mathrm{RV}=2 \cdot 1 \text { to } 3.6\end{array}$ & $\begin{array}{l}\text { (a) Small heart } \\
\text { LV +S: normal range } \\
\text { RV: normal range } \\
(\mathrm{LV}+\mathrm{S}) / \mathrm{RV}>3.6\end{array}$ & $\begin{array}{l}\text { (a) Small heart } \\
\mathrm{LV}+\mathrm{S}: \text { normal range } \\
\mathrm{RV}: \text { normal range } \\
(\mathrm{LV}+\mathrm{S}) / \mathrm{RV}<2 \cdot 1\end{array}$ & $\begin{array}{l}\text { (a) Small heart } \\
\mathrm{LV}+\mathrm{S}=175 \text { to } 220 \mathrm{~g} \\
\text { (individual }<70 \text { inches tall) } \\
\mathrm{RV}>60 \mathrm{~g} \text { (individual }<70 \\
\text { inches tall) } \\
\text { (Biatrial hypertrophy) } \\
\text { (LV + S)/RV: normal } \\
\text { (b) Large heart } \\
\mathbf{L V}+\mathrm{S}>220 \mathrm{~g} \\
\mathrm{RV}>75 \mathrm{~g} \\
\text { (LV }+\mathrm{S}) / \mathrm{RV} \text { : normal or high }\end{array}$ \\
\hline
\end{tabular}

$L V$, left ventricular weight; RV, right ventricular weight; $S$, interventricular septal weight. 
Table 2 Classification of 133 patients on the basis of post-mortem data

\begin{tabular}{llll}
\hline & $\begin{array}{l}\text { Training } \\
\text { group } \\
\text { (51 cases) }\end{array}$ & $\begin{array}{l}\text { Test group } \\
\text { (82 cases) }\end{array}$ & $\begin{array}{l}\text { Total } \\
\text { (133 cases) }\end{array}$ \\
\hline Normal & 14 & 27 & 41 \\
Left ventricular hypertrophy & 5 & 11 & 16 \\
Right ventricular hypertrophy & 4 & 7 & 11 \\
Biventricular hypertrophy & 14 & 12 & 26 \\
$\begin{array}{l}\text { Borderline patients } \\
\text { Intraventricular conduction }\end{array}$ & 8 & 14 & 22 \\
$\quad$ defect ${ }^{\star}$ or & 6 & 11 & 17 \\
Bundle-branch block & 6 & 11 & \\
\hline
\end{tabular}

${ }^{\star} \mathrm{QRS}$ duration $>0 \cdot 12 \mathrm{~s}$, no bundle-branch block.

3.6. Occasionally, this ratio was normal, thereby excluding the diagnosis of left or right ventricular hypertrophy, but the weights were not consistent with the remaining diagnoses of normal or biventricular hypertrophy. Such a finding was placed in the borderline group. Because of the possibility of an error in weights of the order of 1 or $2 \mathrm{~g}$ which could occur because of difficulty in removing completely all the epicardial fat, it was decided that an $(\mathrm{LV}+\mathrm{S}) / \mathrm{RV}$ ratio which lay within the range 2 to 2.2 or 3.5 to 3.7 would be regarded as borderline since $2 \cdot 1$ to $3 \cdot 6$ was the normal range.

There remained 45 hearts when those with corresponding electrocardiograms with intraventricular conduction defect were excluded. Because there were eight hearts in the borderline group, a total of 37 hearts with a definite categorisation of normal, left ventricular, right ventricular, or biventricular hypertrophy was available for the development of a scoring technique.

The usual indices of ventricular hypertrophy were assessed. These included the amplitude of the $\mathbf{R}$ wave in the anterolateral lead, the depth of the $S$ wave in the anteroseptal lead (equivalent to the $S$ wave in lead V2), the QRS magnitude, and orientation together with the other selected variables. Of particular interest was the QRS-T angular difference in the transverse plane. It has been shown by others that a common finding in left ventricular hypertrophy is that the $Q R S$ vector and $T$ vector are oppositely directed. ${ }^{5}$ Similar reasoning was used for right ventricular hypertrophy with the depth of the $S$ wave in the anterolateral lead, the amplitude of the $R$ wave in the anteroseptal lead, and the $R / S$ ratio on this lead also being prominent among the criteria evaluated. Various correlations between electrocardiographic measurements and heart weights were also calculated to assess the relative merits of individual variables. Likewise, electrocardiographic scores were correlated with weights in order to determine critical scoring values. Measurements were not age related since all patients were over 30 years of age which is the top age range of normal stratification previously used. ${ }^{29}$

The net effect was to produce a score for each of the criteria considered. Table 3 shows the scores which were finally developed. A total of four points was regarded as "borderline", five points "probable", and six points "definite" ventricular hypertrophy. This applies to left, right, and biventricular hypertrophy.

Table 3 Electrocardiograph scoring system for diagnosis of ventricular hypertrophy

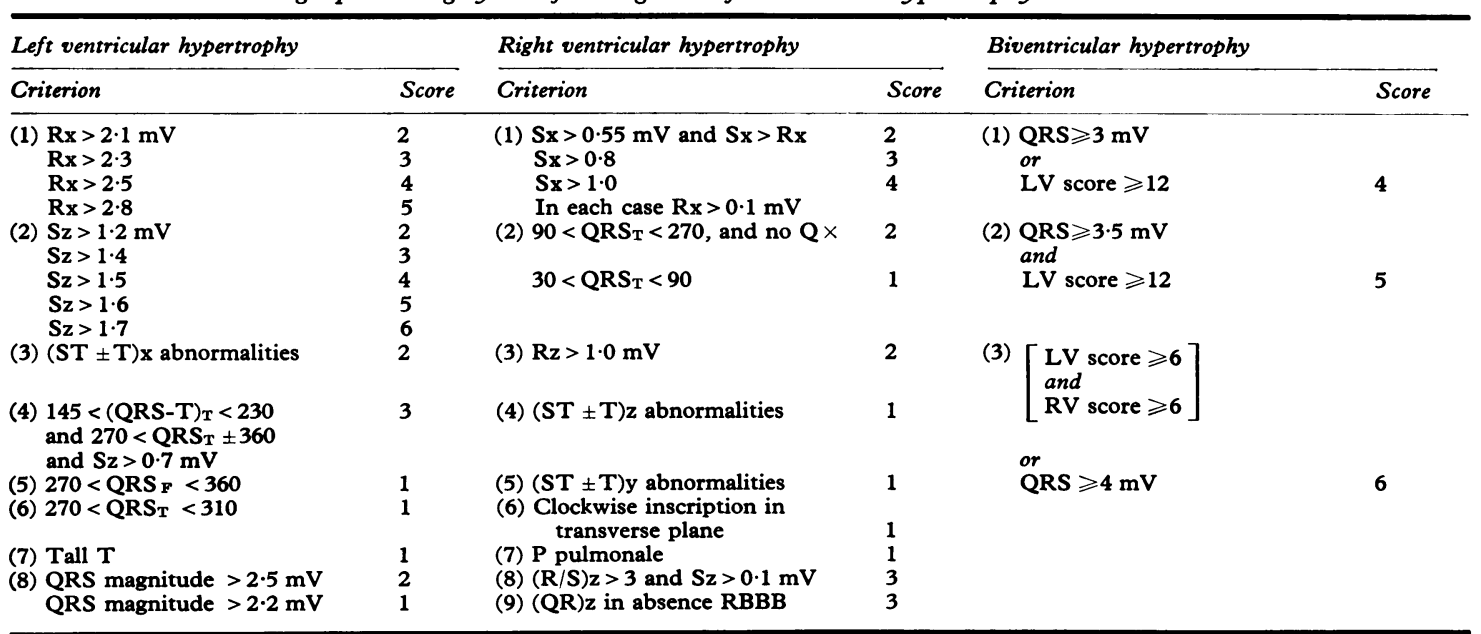

Score 4: borderline evidence of ventricular hypertrophy.

Score 5: probable evidence of ventricular hypertrophy.

Score 6: definite evidence of ventricular hypertrophy.

NB. Lead $Z$ is directed positively to the anterior chest of V2. 
A further group of 82 hearts was available for use as a test group (Table 2). As previously, corresponding electrocardiograms which showed intraventricular conduction defect were excluded from the study, and it was also necessary to form a borderline group. There were 57 hearts which were either normal, or with left, right, or biventricular hypertrophy, and 14 in the borderline group.

\section{Results}

While the results from the training group are not of great value, they are of certain relevance in indicating that the scoring technique was developed to produce maximum specificity. Table 4 shows the results for right ventricular hypertrophy where the specificity of 100 per cent was readily obtained with a corresponding sensitivity of 67 per cent. For left ventricular hypertrophy the corresponding figures for specificity were 94 per cent and for sensitivity 74 per cent. For biventricular hypertrophy, the specificity was 100 per cent with a corresponding sensitivity of 64 per cent. The latter was based on 14 hearts with evidence of biventricular hypertrophy. All these results are based on the left ventricular, right ventricular, or biventricular scores of four or more points being electrocardiographic evidence of hypertrophy. The test group results are shown in Table 5. For right ventricular hypertrophy, the sensitivity was 53 per cent while the specificity dropped to 90 per cent. For left ventricular hypertrophy a similar occurrence was found, with specificity being 91 per cent and sensitivity being 65 per cent. For combined ventricular hypertrophy the specificity was 93 per cent with a sensitivity of 42 per cent.

There were significant correlations between $(L V+S)$ and $Q R S$ magnitude, $R_{x}, S_{z}, R_{x}+S_{z}$ in the training, combined test and training, and test groups (excluding the borderline and conduction defect cases) (Table 6). There was a significant correlation between $S_{x}$ and right ventricular weight in all groups and between $R_{z}+S_{x}$ and the right ventricle in the test and total groups. $R_{z}$ also correlated with the right ventricular weight as shown in Table 6.

Table 4 Sensitivity and specificity in training group

\begin{tabular}{llr}
\hline & Sensitivity & \multicolumn{1}{c}{ Specificity } \\
\hline Left ventricular hypertrophy & $74 \%(14 / 19)$ & $94 \%(17 / 18)$ \\
Right ventricular hypertrophy & $67 \%(12 / 18)$ & $100 \%(19 / 19)$ \\
Biventricular hypertrophy & $64 \%(9 / 14)$ & $100 \%(23 / 23)$ \\
\hline
\end{tabular}

Note: There were 37 cases excluding those in the conduction defect and borderline groups. Patients with biventricular hypertrophy are included in the right ventricular and left ventricular hypertrophy categories.
Table 5 Sensitivity and specificity in test group

\begin{tabular}{lll}
\hline & Sensitivity & Specificity \\
\hline Left ventricular hypertrophy & $65 \%(15 / 23)$ & $91 \%(31 / 34)$ \\
Right ventricular hypertrophy & $53 \%(10 / 19)$ & $90 \%(34 / 38)$ \\
Biventricular hypertrophy & $42 \%(5 / 12)$ & $93 \%(42 / 45)$ \\
\hline
\end{tabular}

Note: There were 57 cases excluding those in the conduction defect and borderline groups. Patients with biventricular hypertrophy are included in the left ventricular and right ventricular hypertrophy categories.

The electrocardiogram point scores for left and right ventricular hypertrophy were correlated with the $(L V+S)$ and right ventricular weights, respectively. Highly significant correlations $(p<0.001)$ were found in the test group (see Figs.) and in the training group for left ventricular hypertrophy score only (borderline cases and conduction defects excluded). The right ventricular score did not correlate significantly with right ventricular weight in the training group, but did so in the test group $(r=0.39, p<0.01)$.

\section{Discussion}

While it is well known that there must be a continuum between normal and abnormal, it nevertheless was a salutary lesson to discover the difficulties of classifying hearts in the various categories even with post-mortem data. One example of the problem was a male patient, aged 72 years, height $180 \mathrm{~cm}$ ( 5 feet 11 inches). His left ventricular weight was $150 \mathrm{~g}$, septal weight $70 \mathrm{~g}$, and right ventricular weight $70 \mathrm{~g}$. This gives an $(\mathrm{LV}+\mathrm{S}) / \mathrm{RV}$ ratio of 3.14 which is normal. Since the patient was over $178 \mathrm{~cm}$ ( 5 feet 10 inches), the weight of $220 \mathrm{~g}$ for the LV+S weight was abnormal (see Table 1). The right ventricular weight of $70 \mathrm{~g}$, however, was normal for a patient of this height. ${ }^{22}$ These measure-

Table 6 Correlation of electrocardiographic variables with cardiac weights in 94 patients excluding those in conduction defect and borderline groups

\begin{tabular}{|c|c|c|c|c|}
\hline & & \multicolumn{3}{|c|}{ Correlation coefficient $(\boldsymbol{r})$} \\
\hline & & $\begin{array}{l}\text { Training } \\
\text { group } \\
\text { (37 cases) }\end{array}$ & $\begin{array}{l}\text { Test } \\
\text { group } \\
(57 \text { cases })\end{array}$ & $\begin{array}{l}\text { Combined } \\
\text { group } \\
\text { (94 cases) }\end{array}$ \\
\hline $\begin{array}{l}\text { QRS magnitude } \\
\mathbf{R x}+\mathbf{S z} \\
\mathbf{R x} \\
\mathbf{S z} \\
\mathbf{S x} \\
\mathbf{R z} \\
\mathbf{S x}+\mathbf{R z}\end{array}$ & $\begin{array}{l}\text { v } \mathbf{L V}+\mathbf{S} \\
\text { v } \mathbf{L V}+\mathbf{S} \\
\text { v } \mathbf{L V}+\mathbf{S} \\
\text { v } \mathbf{L V}+\mathbf{S} \\
\text { v } \mathbf{R V} \\
\text { v } \mathbf{R V} \\
\text { v } \mathbf{R V}\end{array}$ & $\begin{array}{l}0.629^{\star \star \star} \\
0.704^{\star \star \star} \\
0 \cdot 460^{\star \star} \\
0 \cdot 489^{\star \star} \\
0 \cdot 415^{\star \star} \\
0.435^{\star \star} \\
0.182\end{array}$ & $\begin{array}{l}0.576^{\star \star \star} \\
0.551^{\star \star \star} \\
0.496^{\star \star \star} \\
0 \cdot 292^{\star} \\
0.397^{\star \star} \\
0 \cdot 143 \\
0 \cdot 263^{\star}\end{array}$ & $\begin{array}{l}0.608^{\star \star \star} \\
0.629^{\star \star \star} \\
0 \cdot 481^{\star \star \star} \\
0.373^{\star \star \star} \\
0.397^{\star \star \star} \\
0 \cdot 232^{\star} \\
0.236^{\star}\end{array}$ \\
\hline
\end{tabular}

$\begin{aligned} \star \star \star \star \mathrm{p} & <0.001 \\ \star \star \mathrm{p} & <0.01\end{aligned}$

$\star \mathrm{p}<0.05$. 
ments do not fit the criteria of Bove et al. ${ }^{22}$ for combined ventricular hypertrophy, left ventricular, or right ventricular hypertrophy and this heart was put into the borderline category. The electrocardiogram score in this case was two points each for left ventricular hypertrophy and right ventricular hypertrophy.

There were eight such patients with borderline weights in the training group and a further 14 patients were categorised as borderline in the test group. Since the borderline hearts in the training group were of no value for development of criteria, it is reasonable to place them together with the other 14 hearts in the test group to form a total group of 22 hearts regarded as borderline normal/abnormal. Two of the patients in the borderline group had electrocardiographic evidence of biventricular hypertrophy, eight patients had electrocardiographic evidence of left ventricular hypertrophy, two had electrocardiographic evidence of right ventricular hypertrophy, while the remaining 10 had normal electrocardiograms.

The choice of a minimum value of four for the diagnosis of left ventricular hypertrophy is debatable on the evidence presented in the training group (Fig. 1a). A value of four provides a level of 95 per cent specificity approximately, which is normally the chosen level for the establishment of diagnostic criteria. In order to have improved on this, a level of six would have been needed which would have resulted in 100 per cent specificity for left ventricular hypertrophy, with a slightly reduced sensitivity. The subjective impression gained from use of the scoring system in living subjects with hypertension, rheumatic heart disease, and congenital heart disease, however, suggested that a value higher than four would have greatly decreased the sensitivity in such patients. The choice of this level was borne out in the results of the test group shown in Fig. 1b which indicates the correlation $(r=0.59)$ between the $\mathrm{LV}+\mathrm{S}$ weight and the score for left ventricular hypertrophy for the 57 patients in the test group excluding the borderline group and those patients with intraventricular conduction defects. The correlation is high and extremely significant $(p<0.001)$ and confirms the aim of developing a technique whereby increased score could be interpreted as an increased likelihood of hypertrophy being present.

The gradings of 4,5 , and 6 points have been assigned descriptive terms of borderline, probable, or consistent with left ventricular hypertrophy in the revised computer program for electrocardiographic interpretation. The results presented in the paper have been based on patients with 4 or more points being regarded as having evidence of left

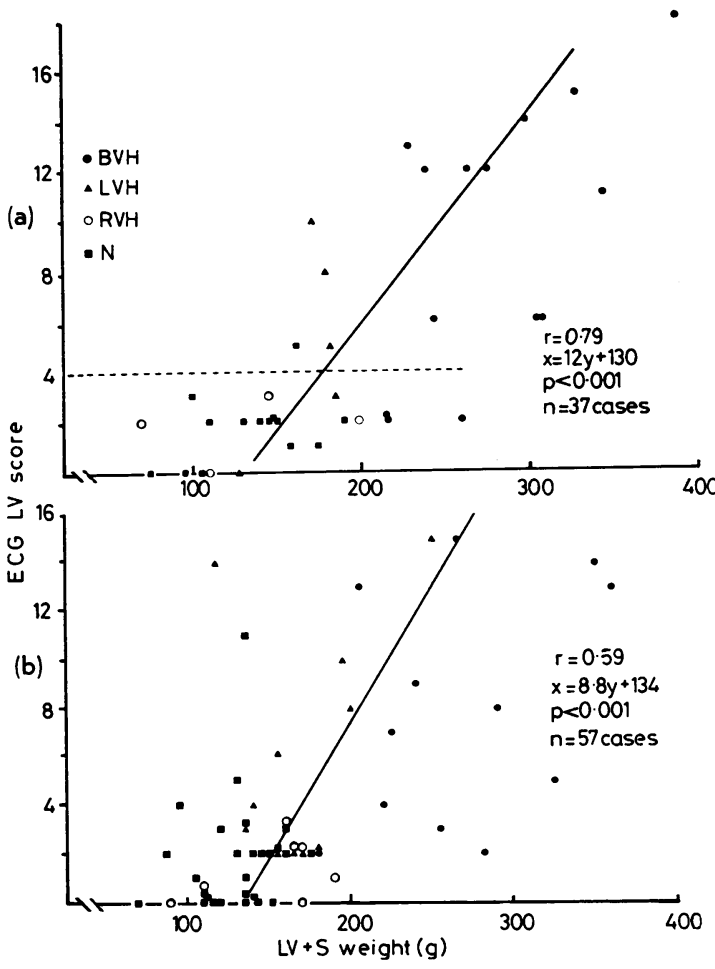

Fig. 1 (a) The relation between the electrocardiographic score for left ventricular hypertrophy $(L V H)$ and $L V+S$ weight determined at necropsy on normal (ロ), $L V H$ ( $\Lambda$, right ventricular hypertrophy $(R V H)(O)$, and biventricular hypertrophy $(B V H)$ (O) subjects in the training group ( 37 cases). (b) The relation between the electrocardiographic score for $L V H$ and $L V+S$ weight determined at necropsy on normal ( $\square), L V H(\Lambda)$, $R V H(O)$, and $B V H(O)$ subjects in the test group (57 cases).

ventricular hypertrophy but it was thought preferable to introduce a grading scheme within the computer program which gave an indication of the likely reliability of the result. The effect of raising the minimum number of points for the diagnosis of left ventricular hypertrophy is shown in Table 7; for example in the training group the specificity of a report of left ventricular hypertrophy ( $\geqslant 6$ points) was 100 per cent. In the test group a report of definite left ventricular hypertrophy was 97 per cent specific. A further two patients with normal heart weights had a score of 4 or 5 points in the test group which resulted in a decreased overall specificity for the diagnosis of left ventricular hypertrophy ( $\geqslant 4$ points) but these patients, therefore, only had electrocardiographic reports of borderline or probable left ventricular hypertrophy. It was felt 
Table 7 Effect of varying minimum score for electrocardiographic diagnosis of hypertrophy

\begin{tabular}{|c|c|c|c|c|c|c|c|}
\hline & & \multicolumn{2}{|l|}{ Score 4} & \multicolumn{2}{|l|}{ Score 5} & \multicolumn{2}{|l|}{ Score 6} \\
\hline & & Sensitivity & Specificity & Sensitivity & Specificity & Sensitivity & Specificity \\
\hline $\begin{array}{l}\text { Training group } \\
\quad(37 \text { cases }) \\
\text { Test group } \\
\quad(57 \text { cases })\end{array}$ & $\begin{array}{l}\text { Left ventricular hypertrophy } \\
\text { Right ventricular hypertrophy } \\
\text { Biventricular hypertrophy } \\
\text { Left ventricular hypertrophy } \\
\text { Right ventricular hypertrophy } \\
\text { Biventricular hypertrophy }\end{array}$ & $\begin{array}{l}\mathbf{7 4} \% \\
\mathbf{6 7} \% \\
\mathbf{6 4} \% \\
\mathbf{6 5} \% \\
\mathbf{5 3} \% \\
\mathbf{4 2} \%\end{array}$ & $\begin{array}{r}94 \% \\
100 \% \\
100 \% \\
91 \% \\
90 \% \\
93 \%\end{array}$ & $\begin{array}{r}74 \% \\
22 \% \\
21 \% \\
61 \% \\
26 \% \\
8 \%\end{array}$ & $\begin{array}{r}94 \% \\
100 \% \\
100 \% \\
94 \% \\
97 \% \\
100 \%\end{array}$ & $\begin{array}{r}68 \% \\
17 \% \\
21 \% \\
57 \% \\
21 \% \\
0 \%\end{array}$ & $\begin{array}{r}100 \% \\
100 \% \\
100 \% \\
97 \% \\
100 \% \\
100 \% \\
\end{array}$ \\
\hline
\end{tabular}

worth while to continue with the grading scheme in order to maximise the sensitivity though slightly diminishing the specificity with a qualification in the computer report.

Similar considerations apply to the interpretation of right ventricular hypertrophy. Fig. 2a shows the results from the training group where a level of 4 points provides 100 per cent specificity. Selection of 3 points would have resulted in a specificity of a little over 90 per cent $(17 / 19)$. With respect to the test group (Fig. 2b), a level of 4 points resulted in detection of four out of seven patients with isolated right ventricular hypertrophy. The inclusion of patients with post-mortem evidence of biventricular hypertrophy resulted in the addition of only one

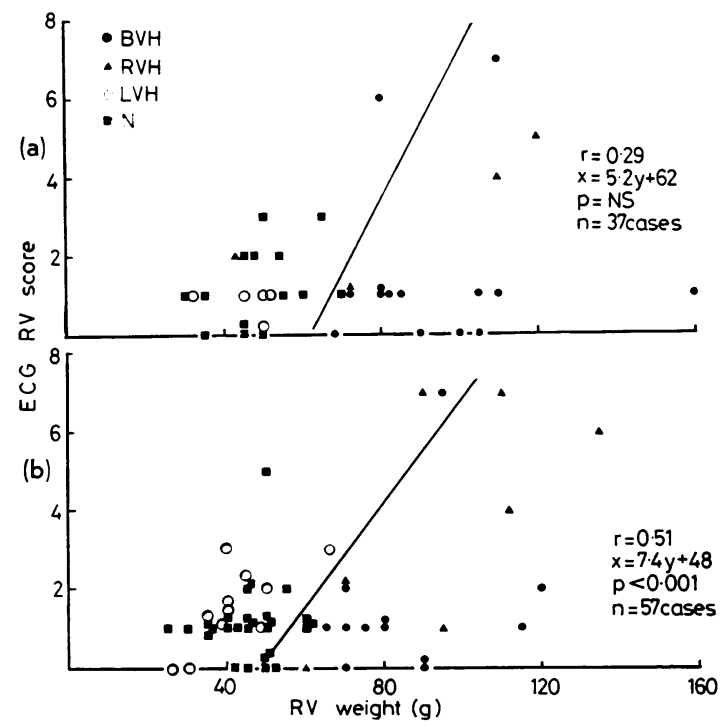

Fig. 2 (a) The relation between the electrocardiographic score for $R V H$ and $R V$ weight determined at necropsy

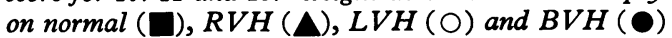
subjects in training group (37 cases). (b) The relation between the electrocardiographic score for $R V H$ and $R V$ weight determined at necropsy on normal ( $\square)$,

$R V H(\Delta), L V H(O)$, and $B V H(\bigcirc)$ subjects in the test group (57 cases). other diagnosis (five of 19) of right ventricular hypertrophy on the basis of the point scoring technique, that is right ventricle points total $\geqslant 4$. With the use of the total number of points for left ventricular hypertrophy, however, exceeding 12 or the magnitude of the maximum QRS vector $>3 \mathrm{mV}$ as evidence of biventricular hypertrophy, the sensitivity for the detection of right ventricular hypertrophy was increased to 53 per cent (10/19). As previously, the effect of raising the minimum point score for the electrocardiographic diagnosis of right ventricular hypertrophy is shown in Table 7. In summary, sensitivity drops considerably as specificity increases.

The criteria for combined ventricular hypertrophy were based in the light of experience of detecting right ventricular hypertrophy in the training group. No additional criteria which were evaluated and which might be expected to improve the sensitivity of right ventricular hypertrophy had any noticeable effect but there was clearly a trend that with increased total heart weight, and hence increased points for the left ventricle as seen from the correlation shown in Fig. 3a, the diagnosis of combined ventricular hypertrophy could be made from a knowledge of the left ventricular score. There was a highly significant correlation between total ventricular weight and left ventricular score $(r=0.76, p<0.001)$ in the training group of 45 patients. Four of the five patients who were diagnosed by the scoring technique in the test group as having biventricular hypertrophy had a left ventricular score $\geqslant 12$ points (Fig. $3 \mathrm{~b}$ ). The effect was to obtain a sensitivity for diagnosing bioventricular hypertrophy of 42 per cent $(5 / 12)$. While this is not high, it has to be compared with a sensitivity of 4 per cent for biventricular hypertrophy using our criteria in use before the study. This percentage was derived from a study of the 94 patients in the training and test groups (excluding those with intraventricular conduction defect or classed as borderline) since the old criteria were developed several years previously without recourse to any of these patients.

The improvement in our diagnosis of biven- 


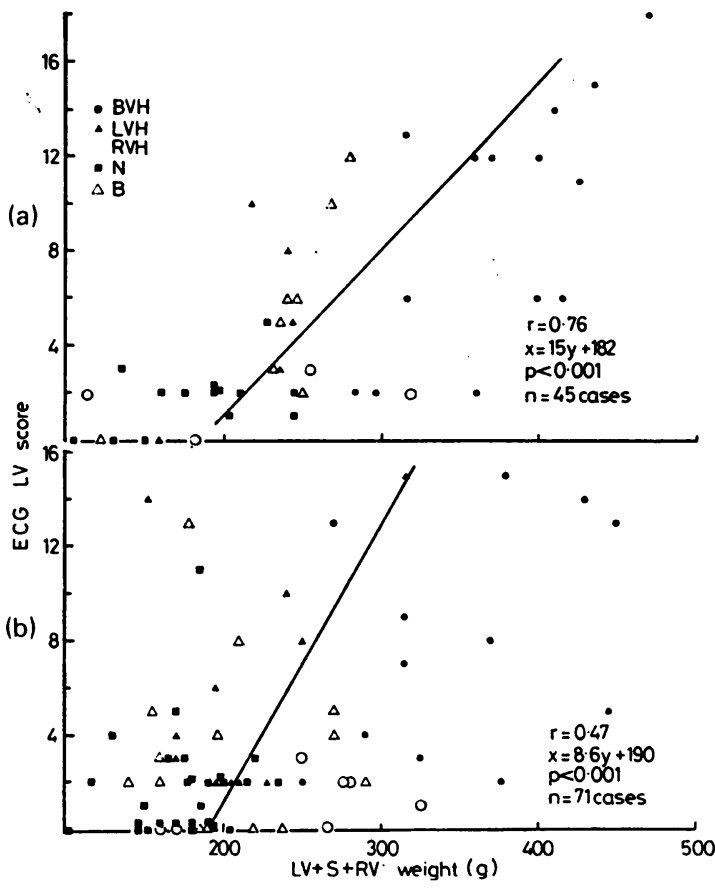

Fig. 3 (a) The relation between the electrocardiographic score for $L V H$ and total ventricular weight determined at necropsy from the training group (including borderline patients) for total 45 cases. $B V H$, biventricular hypertrophy; $\Delta$ LVH, left ventricular hypertrophy; $\bigcirc R V H$, right ventricular hypertrophy; $\mathbb{N}$, normal; $\triangle B$, borderline. (b) Relation between the

electrocardiographic score for $L V H$ and total ventricular weight determined at necropsy from the test group (including borderline patients) for total 71 patients.

tricular hypertrophy using the scoring technique is tenfold. This improved sensitivity was obtained at minimal loss of specificity, that is 93.3 per cent as opposed to $97 \cdot 1$ per cent with the old criteria. The predictive value ${ }^{\star}$ changed noticeably from 33.3 per cent with the old criteria to 62.5 per cent with the new criteria.

Similar considerations apply to the diagnosis of left ventricular hypertrophy and right ventricular hypertrophy using the old criteria in use at the start of the study. These criteria were based on binary decision methods such as a positive diagnosis of left ventricular hypertrophy being made when the $R$ wave in lead $X$ was greater than $2.1 \mathrm{mV}$ but a normal electrocardiogram if the amplitude was less (assuming no other abnormalities). The old criteria for left ventricular hypertrophy gave a sensitivity of 60 per cent with a corresponding $\star$ Predictive value $=$ true positives $/$ (true positives + false positives $)$. specificity of 83 per cent. Again the new criteria have produced an improvement in sensitivity of a few per cent together with almost 10 per cent increase in specificity (see Table 8 ). The latter aspect is particularly important.

The sensitivity for right ventricular hypertrophy using the old criteria was a poor 17 per cent with the corresponding specificity of 93 per cent. With the introduction, however, of the new criteria including those for biventricular hypertrophy the sensitivity for right ventricular hypertrophy increased to almost 53 per cent, with a small reduction in specificity to approximately 90 per cent.

Of the 133 patients studied, 17 had some form of conduction defect with the QRS duration exceeding $0 \cdot 12 \mathrm{~s}$. Three had left bundle-branch block and all of these had biventricular hypertrophy. Five had an intraventricular conduction defect, four having biventricular and one left ventricular hypertrophy. The remaining nine subjects with right bundlebranch block included four with normal heart weights. Of the 17 patients, 11 were in the test group and the inclusion of left bundle-branch block or intraventricular conduction defects as a criterion for borderline biventricular hypertrophy would have increased the sensitivity of biventricular hypertrophy criteria from 42 to 59 per cent with no loss of specificity. When criteria were formulated using the training group, however, where again a similar pattern was apparent, it was felt that the available reports ${ }^{15}{ }^{25}$ did not support the present finding of intraventricular conduction defects or left bundle-branch block as a highly specific indicator of left ventricular or biventricular hypertrophy. More recently ${ }^{30}$ it has been suggested that the Sokolow and Lyon criteria ${ }^{2}$ for left ventricular hypertrophy can apply in the presence of left bundle-branch block though specificity is low. In our view, however, this is a meaningless conclusion since diagnostic criteria should have a specificity of at least 90 per cent and preferably 95 per cent.

The effect of constitutional variables on the electrocardiogram has recently been restudied. ${ }^{31}$ To have attempted to subdivide the training group

Table 8 Improvement in sensitivity and specificity of new diagnostic electrocardiographic criteria, compared with old criteria

\begin{tabular}{|c|c|c|}
\hline & $\begin{array}{l}\text { Old criteria } \\
\text { (94 cases) }\end{array}$ & $\begin{array}{l}\text { New criteria } \\
(57 \text { cases })\end{array}$ \\
\hline $\begin{array}{l}\text { Right ventricular hypertrophy } \\
\text { Left ventricular hypertrophy } \\
\text { Biventricular hypertrophy }\end{array}$ & $\begin{array}{l}\text { Sensitivity } 16 \% \\
\text { Specificity } 93 \% \\
\text { Sensitivity } 60 \% \\
\text { Specificity } 83 \% \\
\text { Sensitivity } 4 \% \\
\text { Specificity } 97 \%\end{array}$ & $\begin{array}{ll}\text { Sensitivity } & 53 \% \\
\text { Specificity } & 90 \% \\
\text { Sensitivity } & 65 \% \\
\text { Specificity } & 91 \% \\
\text { Sensitivity } & 42 \% \\
\text { Specificity } & 93 \%\end{array}$ \\
\hline
\end{tabular}


by age and sex at most would have resulted in totals in each subgroup that were too small. Furthermore, the nature of the study was such that the vast majority of hearts reviewed were from the upper end of the age range (mean age $=65$ years as previously stated). Out of interest, however, the results in the test group were divided into two groups, male and female, for each diagnostic category. A better sensitivity was achieved for left ventricular hypertrophy in women $(82 \% \mathrm{v} \mathrm{50 \%})$. This is perhaps contrary to expectation since an identical abnormal voltage in men and women of the same age is probably worthy of a higher score in women who have a lower upper limit of normal voltage than in men in most praecordial leads. ${ }^{32}$ The scoring system presented does not allow for this. Conversely, the sensitivity for right ventricular hypertrophy was much higher in men than in women $(70 \%$ v $33 \%)$. Results for biventricular hypertrophy were comparable. The number of positive diagnoses, however, in each group is too small to draw meaningful conclusions.

Our study has shown that the introduction of scoring techniques for the diagnosis of ventricular hypertrophy has considerably improved the sensitivity for ventricular hypertrophy (left, right, or combined) with a minimal reduction in specificity for right ventricular and biventricular hypertrophy. It is likely that the sensitivity and specificity of criteria will vary with the type of population used for their development and evaluation but further use with the new criteria in the clinical situation appears, at present, to have borne out amply the results obtained in this study.

One other advantage of the criteria is that they can be applied without the use of a computer. Basically all that is involved is measurement of amplitudes together with angles and these can readily be obtained from the scalar presentation of the three orthogonal lead electrocardiogram and from the vector cardiogram. Admittedly computer assistance with the calculation of these measurements is of considerable value but this should not preclude the use of the criteria in the routine situation.

The methods presented in this paper have now been incorporated into a program which is routinely used in Glasgow Royal Infirmary. The next step in the development of criteria will be an attempt to combine the scoring technique for the three orthogonal lead electrocardiographic diagnosis of left ventricular hypertrophy and a similar approach with the 12 lead electrocardiogram, without loss of specificity, using the hybrid lead system ${ }^{33}$ which records the three orthogonal and 12 lead electrocardiograms. Others ${ }^{9}$ have attempted to combine separate analyses of three and 12 lead systems without optimising criteria for the diagnosis of left ventricular hypertrophy but the resulting specificity in isolated left ventricular hypertrophy was $\mathbf{8 0 . 3}$ per cent which is not acceptable. On the evidence of the present and other papers, ${ }^{13}$ it is hoped that scoring techniques applied selectively to a single set of waveforms (the hybrid system) will prove superior.

\section{References}

1 Goldberger E. Unipolar lead electrocardiography. 2nd ed. Philadelphia: Lea \& Febiger, 1949.

2 Sokolow M, Lyon TP. The ventricular complex in left ventricular hypertrophy as obtained by unipolar precordial and limb leads. Am Heart $\mathcal{f}$ 1949; 37: 161-86.

3 Sokolow M, Lyon TP. The ventricular complex in right ventricular hypertrophy as obtained by unipolar precordial and limb leads. Am Heart $\mathcal{f}$ 1949; 38: 273-94.

4 Goldberger E. Unipolar lead electrocardiography and vectorcardiography. 3rd ed. Philadelphia: Lea \& Febiger, 1953.

5 Chou TC, Helm RA. Clinical vectorcardiography. New York: Grune \& Stratton, 1967.

6 Gamboa R, Klingeman JD, Pipberger HV. Computer diagnosis of biventricular hypertrophy from the orthogonal electrocardiogram. Circulation 1969; 39: 72-82.

7 McCaughan D, Littman D, Pipberger HV. Computer analysis of the orthogonal electrocardiogram and vectorcardiogram in 939 cases with hypertensive cardiovascular disease. Am Heart $f$ 1973; 85: 467-82.

8 Romhilt DW, Bove KE, Norris RJ, Conyers E, Conradi S, Rowlands DT. A critical appraisal of the electrocardiographic criteria for the diagnosis of left ventricular hypertrophy. Circulation 1969; 40: 185-95.

9 Talbot S, Kilpatrick D. Diagnostic criteria for left ventricular hypertrophy. In: Macfarlane PW, ed. Progress in electrocardiology. Tunbridge Wells: Pitman Medical, 1979: 534-7.

10 Romhilt DW, Estes EH Jr. A point-score system for the ECG diagnosis of left ventricular hypertrophy. Am Heart f 1968; 75: 752-8.

11 Geva B, Elkayam U, Frishman W, Terdiman R, Laniado S. Determination of left ventricular wall thickening in patients with chronic systemic hypertension. Chest 1979; 76: 557-61.

12 Holt JH Jr, Barnard ACL, Kramer JO Jr. Quantitative electrocardiography using a multiple dipole method. In: Abel H, ed. Advances in cardiology. Vól. 16. Basel: Karger, 1976: 117-20.

13 Liu CK, DeCristofaro D. Sensitivity and specificity of electrocardiographic evaluation of LVH in 364 unselected autopsy cases. Am Heart f 1968; 76: 596-604.

14 Allenstein BJ, Mori H. Evaluation of electrocardiographic diagnosis of ventricular hypertrophy based 
on autopsy comparison. Circulation $1960 ; 21$ : 401-12.

15 Scott RC. The correlation between the electrocardiographic patterns of ventricular hypertrophy and the anatomic findings. Circulation 1960; 21: 256-91.

16 Myers GB, Klein HA, Stofer BE. The electrocardiographic diagnosis of right ventricular hypertrophy. Am Heart f 1948; 35: 1-40.

17 Levine HD, Phillips E. An appraisal of the newer electrocardiography: correlations in 150 consecutive autopsied cases. $N$ Engl f Med 1951 ; 245: 833-42.

18 Whipple GH, Levine HD. The vectorcardiographic diagnosis of combined ventricular hypertrophy (abstract). Clin Res Proc 1955; 3: 109-10.

19 Hiroki T. Vectorcardiographic analysis of combined ventricular hypertrophy in adult patients. In: Abel $\mathrm{H}$, ed. Advances in cardiology. Vol. 16. Basel: Karger, 1976: 370-75.

20 Goldstein M, Sajet M, Delcambre Y, Demeester M. New parameters for automatic VCG analysis in the C.I.M.H.U.B. program. In: Macfarlane PW, ed. Progress in electrocardiology. Tunbridge Wells: Pitman Medical, 1979: 379-81.

21 Macfarlane PW, Fraser RS, Boyce B, Lawrie TDV. New 3 orthogonal lead ECG criteria for ventricular hypertrophy. In: Antaloczy Z, ed. Modern electrocardiology. Amsterdam: Excerpta Medica, 1978: 41721.

22 Bove KE, Rowlands DT, Scott RC. Observations on the assessment of cardiac hypertrophy utilizing a chamber partition technique. Circulation 1966; 33: $558-68$.

23 Fulton RM, Hutchinson EC, Jones AM. Ventricular weight in cardiac hypertrophy. Br Heart $\mathcal{f} 1952$; 14: 413-20.

24 Reiner L, Mazzoleni A, Rodriguez FL, Freudenthal RR. The weight of the human heart. I. "Normal" cases. Arch Pathol 1959; 68: 57-73.
25 Mazzoleni A, Wolff R, Wolff L, Reiner L. Correlation between component cardiac weights and electrocardiographic patterns in 185 cases. Circulation $1964 ; 30$ : 808-29.

26 Macfarlane PW. A modified axial lead system for orthogonal lead electrocardiography. Cardiovasc Res 1969; 3: 510-5.

27 Macfarlane PW, Peden J, Lennox G, Watts MP, Lawrie TDV. The Glasgow system. In: Van Bemmel JH, Willems JL. eds. Trends in computerprocessed electrocardiograms. Amsterdam: North Holland, 1977: 143-50.

28 Macfarlane PW. Computer studies in electrocardiography. Ph.D. Thesis: University of Glasgow, 1970.

29 Macfarlane PW, Lorimer AR, Lawrie TDV. Normal ranges of modified axial lead system electrocardiogram parameters. Br Heart $\mathcal{f} 1971$; 33: 258-65.

30 Cokkinos DV, Demopoulos JN, Heimonas ET, Mallios C, Papazoglou N, Vorides EM. Electrocardiographic criteria of left ventricular hypertrophy in left bundle branch block. Br Heart $\mathcal{f} 1978 ; 40$ : 320-4.

31 Pipberger HV, Pipberger HA. The influence of constitutional variables on electrocardiographic diagnosis. In: Wolf $\mathrm{HK}$, Macfarlane $\mathrm{PW}$, eds. Optimization of computer ECG processing. Amsterdam: North Holland, 1980: 241-45.

32 Simonson E. Differentiation between normal and abnormal in electrocardiography. St. Louis: CV Mosby, 1961.

33 Macfarlane PW. A hybrid lead system for routine electrocardiography. In: Macfarlane PW, ed. Progress in electrocardiology. Tunbridge Wells: Pitman Medical, 1979: 1-5.

Requests for reprints to Dr P W Macfarlane, University Department of Medical Cardiology, Royal Infirmary, Glasgow GF OSF. 